\title{
Israel y Atenas o ¿a quién pertenece la razón anamnética? Sobre la unidad en la diversidad multicultural*
}

\author{
JÜRGEN HABERMAS \\ Universidad de Francfort
}

Frente a quienes afirman que la «razón anamnetica» es una cultura ausente del pensamiento occidental, Habermas defiende en este artículo que es la arazón comunicativas su natural heredera. $\mathrm{Ha}$ bermas reconoce que a esa cultura que viene de Jerusalén debe la filosofía eu- ropea la inspiración de sus topoi más sobresalientes: los de sujeto, autonomía, liberacion, historia... Pero en tiempos postmetafísicos sólo la pragmática universal de su "razón comunicativa" puede hacerse con el potencial semántico inserto en la cultura del monoteísmo judío.

El pensamiento de Johann Baptist Metz también a mí me fascina porque, pasando por alto ciertas distancias, reconozco en él intenciones comunes. El hecho de que a alguien que, desde una perspectiva filosófica, adopta la posición de un ateísmo metódico se le planteen las mismas cuestiones que a un téblogo, resulta menos sorprendente que el paralelismo de las respuestas. Intentando conseguir cierta claridad en torno a estos paralelismos quiero mostrar mi agradecimiento al télogo contemporáneo.

Metz, refiriéndose a su propia biografía, ilustró en su día el hecho de la simultaneidad de lo no-simultáneo con el que nos topamos hoy en el abanico multicultural de una sociedad mundial descentrada: «Procedo de una pequeña ciudad bávara profundamente católica. Viniendo de allí, se viene de muy lejos. Es como si uno no hubiera nacido hace cincuenta años (o hace sesenta y cinco) sino en algún punto en los márgenes crepusculares de la edad media. Me costó mucho esfuerzo descubrir cosas que otros, que "la sociedad", según parece, hacía tiempo que ya habían descubierto [...]: la democracia en la cotidianidad política, por ejemplo, el trato con una esfera pública difusa, reglas de juego para el conflicto incluso en la vida familiar, etc. Mucho resultaba extraño y, en realidad, continuó siendo siempre extraño". ${ }^{1}$ Ante este trasfondo de experiencias, Metz se ha opuesto a una posición meramente defensiva de la Iglesia católica frente a la modernidad y ha abogado por una participación productiva en los procesos de la Ilustración burguesa y postburguesa. Si la visión bíblica de la salva-

* Traducción de Pere Fabra. 
ción no significa solamente la redención de la culpa individual sino que incluye también la liberación colectiva de situaciones de miseria y de opresión (y, por tanto, junto al elemento místico contiene también un elemento político), la marcha escatológica hacia la salvación de los que sufren injustamente entra en contacto con los impulsos de la historia de la libertad en la modernidad europea.

Pero tan graves consecuencias tiene la insensibilidad frente al potencial emancipatorio de esta historia como la ceguera frente a la dialéctica de la Ilustración. A la Ilustración le ha quedado oculto durante demasiado tiempo el reverso bárbaro de su propio espejo, y ello porque a la luz de sus pretensiones universalistas ha pasado por alto el núcleo particularista de su origen occidental. Este racionalismo empedernido, aferrado a sí mismo, se ha transformado en la muda violencia de una civilización capitalista de ámbito mundial que asimila las culturas ajenas y relega al olvido las propias tradiciones. El cristianismo, que creyó poder servirse de esta civilización como un sinocente catalizador para la propagación universal de su esperanza", y la Iglesia, que creyó que podía enviar sus misioneros siguiendo las huellas de los colonizadores europeos, participaron involuntariamente en esta dialéctica de desencantamiento y pérdida de memoria. De ahí se explica el diagnóstico que hace Metz de la teología y la exigencia práctica con la que confronta a su Iglesia.

El diagnóstico dice así a través de la razón filosófica de procedencia griega, un cristianismo helenizado se ha dejado distanciar tanto de su propio origen en el espíritu de Israel que la teología se ha vuelto insensible frente al grito del sufrimiento y frente a la demanda de justicia universal (1 y 2). Y la exigencia es del siguiente tenor: la iglesia eurocéntrica surgida del suelo del helenismo debe superar su autocomprension monocultural y, teniendo presente su contexto judaico original, desplegarse como una iglesia universal culturalmente policéntrica (3).

\section{Israel vs. Atenas}

Metz no se cansa de reclamar para el cristianismo la herencia de Israel. "Jesús no fue cristiano, sino judio.» Con esta provocativa fórmula no se opone solamente al antisemitismo cristiano y le pasa cuentas a la ecclesia triumphans por su actitud victoriosa, profundamente cuestionable, frente a una sinagoga cegada y humillada; ${ }^{2}$ con ello se rebela sobre todo contra la apatía de una teología que parece no haberse visto afectada por Auschwitz. ${ }^{3}$ Esta crítica obedece a un impulso práctico-existencial. Pero significa también que un cristianismo helenizado, al rechazar su origen judaico, se ha separado de la fuente de la razón anamnética y se ha convertido en expresión de una razón idealista y errática, incapacitada para la memoria y el recuerdo histórico. Quien entienda el cristianismo "agusti- 
nianamente» como síntesis de razón y fe -proviniendo la razón de Atenas y la fe de Israel- está seccionando, partiendo en dos, el espíritu del cristianismo. ${ }^{4}$ Frente a la división del trabajo entre la razón filosofica y la fe religiosa, Metz insiste en el contenido racional de la tradición de Israel; concibe la fuerza de la rememoración histórica como un elemento de la razón: «Esta razón anamnética se resiste al olvido, incluso al olvido del olvido que anida en toda simple historización del pasados. ${ }^{5}$ Desde este punto de vista la filosofía de raíz griega aparece como administradora de la Ratio, de las fuerzas de un entendimiento (Verstand) que es hecho entrar en razón sólo mediante el vínculo con la memoria que se remite a Moisés y a su promesa. En este sentido, una teología que partiendo de su alienación helenística regresa a sus propios orígenes tiene, frente a la filosofía, la ultima palabra: «[esta teología] apela al nexo indisoluble entre ratio y memoria (expresado en términos modernos: a la fundamentación de la razón comunicativa en la razón anamnética) ${ }^{6}{ }^{6}$

Si se observa este enunciado a contraluz filosófica, no es sólo la relación de fundamentación lo que suscita contradicciones. Tambiến resulta demasiado simple la imagen bosquejada de una tradición filosófica que, sin duda, no se agota en el platonismo, sino que en el curso de su historia ha hecho suyos contenidos de la tradición judeo-cristiana y, mediante la herencia de Israel, se ha visto conmocionada hasta lo más hondo de sus raíces griegas. Ciertamente que el idealismo filos6fico desde S. Agustín hasta Hegel, pasando por Sto. Tomás de Aquino, ha producido aquella síntesis mediante la cual el Dios con el que Job se ve confrontado se ha transformado en el concepto de Dios de los filósofos. Pero la historia de la filosofía no es solamente la del platonismo, sino también la de la protesta frente al mismo. Estas protestas, bien hayan aparecido bajo el signo del nominalismo o del empirismo, del individualismo o del exístencialismo, del negativismo o del materialismo histórico, pueden concebirse como otros tantos intentos de recuperar el potencial semántico del pensamiento salvífico en el universo del habla fundamentadora. Con ello han penetrado en la filosofia intuiciones prácticas que de suyo son ajenas al pensamiento ontologico y a las transformaciones que éste ha sufrido en términos de teoría del conocimiento y de filosofía del lenguaje.

Metz reúne estos motivos no-griegos en el foco único del acto de rememorar (Eingedenkens). Entiende la fuerza del recuerdo en el sentido de Freud, como la fuerza analítica del «traer a consciencia», pero sobre todo en el sentido de Benjamin, como la fuerza mística de una reconciliación retroactiva. El acto de rememorar, de mantener el recuerdo, salva de la ruina aquello que no queremos perder y que, sin embargo, se halla en el mayor de los peligros. Este concepto religioso de «salvación» excede sin duda el horizonte de aquello que la filosofía puede hacer plausible bajo las condiciones del pensamiento postmetafísico. Pero a partir del concepto de 
rememoración salvadora, se abre el campo de aquellas experiencias y motivos religiosos que tuvieron que hacerse oír durante largo tiempo ante las puertas del idealismo filosofico hasta que finalmente fueron tomados en serio y, desde dentro, pudieron sembrar inquietud en una razón dirigida en principio sólo al cosmos. Pero no todo quedo en inquietud. En el curso de una evolución que conduce desde la contemplación intelectual del cosmos hasta la razón encarnada linguíisticamente, pasando por la autorreflexión del sujeto cognoscente, el Logos griego se ha transformado. Actualmente ya no se centra solamente en la relación cognitiva con el mundo -en el ente como ente, en el conocer del conocer o en el significado de enunciados que pueden ser verdaderos o falsos. Lo que ha desplegado toda su fuerza también dentro de la filosofía y ha posibilitado que la razón argumentativa sea receptiva a las experiencias prácticas de la amenazada identidad de seres que existen históricamente es más bien la idea de una Alianza que augura al pueblo de Dios y a cada uno de sus miembros una justicia que se impone a toda una historia de sufrimiento; es la idea de una alianza que engarza libertad y solidaridad en el horizonte de una intersubjetividad integra e incólume.

Sin esta infiltración de ideas de origen genuinamente judaico y cristiano en la metafísica griega no hubiéramos podido constituir aquel entramado de conceptos específicamente modernos que convergen en un concepto de razón a la vez comunicativa e históricamente situada. Pienso en el concepto de libertad subjetiva y en la exigencia de igual respeto para todos y cada uno, incluso y precisamente para aquel que por su particularidad y su diferencia nos resulta más ajeno. Pienso en el concepto de autonomía, de una autovinculación de la voluntad en virtud de una intelección moral que depende de relaciones de reconocimiento recíproco. Pienso en el concepto de un sujeto socializado que se individualiza a lo largo de su vida y que como individuo insustituible es al mismo tiempo miembro de una comunidad, es decir, sólo puede llevar una auténtica vida propia en convivencia solidaria con los otros. Pienso en el concepto de la liberación, tanto en el sentido de emancipación de condiciones humillantes como en el sentido de proyecto utópico de una forma de vida lograda. La irrupción del pensamiento histórico en la filosofía ha propiciado finalmente la comprensión del carácter «emplazadon del tiempo vital, nos ha hecho conscientes de la estructura narrativa de la historia en la que nos vemos envueltos y del carácter acaecido de todo aquello que nos sucede. A ello debe añadirse también la consciencia de falibilidad de la mente humana y de la contingencia de las condiciones bajo las cuales ésta sigue sosteniendo todavía pretensiones incondicionadas.

La tensión entre el espíritu de Atenas y la herencia de Israel no ha tenido menos consecuencias en la filosofía que en la teología. Pero si el pensamiento filosófico no se resuelve simplemente en la labor sintética de 
aquel idealismo que llevó al paleocristianismo de Occidente -concebido eclesialmente- a ser pensado en términos teológicos, entonces la crítica al cristianismo helenizado tampoco puede dirigirse contra la razón argumentativa "per se», ni contra la razón impersonal de los filósofos en cuanto tal. También la anamnesis y la narración pueden ofrecer razones e impulsar con ello el discurso filosofico, aunque no decidan la marcha del mismo. Si bien la razón profana se mantiene escéptica frente a la causalidad mística de un acto de rememoración inspirado en términos salvíficos y no otorga crédito alguno a la mera promesa de restitución, no por ello es necesario que los filosofos dejen solamente en manos de los teólogos aquello que Metz llama la "razón anamnética». Quiero aclarar esto refiriéndome a dos cuestiones que para Metz son de especial interés en términos teológicos o de política eclesiástica.

\section{El problema de la teodicea}

La cuestión relativa a la salvación de los que sufren injustamente es quizá el motor más importante que mantiene activo el discurso sobre Dios. Metz se revuelve decididamente contra una depotenciación platonizante de esta cuestión que, después de Auschwitz, se plantea a los cristianos con más radicalidad que nunca. ${ }^{7}$ Fueron de nuevo los medios de reflexión de la tradición griega los que permitieron diferenciar el Dios redentor del Dios creador del Antiguo Testamento, al que se exoneraba así de la responsabilidad por las barbaridades de una humanidad pecadora. Dios mismo no debía estar implicado en su creación «transida de dolor». Contra esta mitigación idealista del sufrimiento evoca Metz una "cultura de la extrañeza", una cultura del recuerdo que mantiene vivo, sin falsa necesidad de consuelo, el desasosiego existencial propio de la interpelación vehemente a Dios, estimulando con ello la esperanza - alentada escatológicamente- y la sensibilidad por un futuro que, aunque en suspenso, llega ya hasta la actualidad. ${ }^{8}$ Según la doctrina nietzscheana del eterno retorno, la esperanza bíblica en el futuro no debe quedar disuelta en el elemento de una eternidad entendida en términos griegos. ${ }^{9}$

Incluso para esta protesta, que alcanza hasta los ámbitos más profundos de la experiencia religiosa, se encuentra un paralelismo en aquella corriente subterránea del pensamiento filosófico que, frente al intento neoplatónico de establecer una gradación entre lo bueno y lo verdadero, insiste en la positividad y en el sentido propio de lo negativo. Igual que ocurre con la teología, que llevada hasta el extremo acaba en escatología, también esta tradición - que desde Jakob Böhme, pasando por Baader, Schelling y Hegel llega hasta Bloch y Adorno- quiere convertir la experiencia de la negatividad de lo existente en la fuerza dialéctica impulsora de una reflexión que debe romper con el dominio de lo pasado sobre lo futuro. Dado 
que la filosofía no parte de la premisa de un Dios a la vez omnipotente y justo, resulta claro que no puede reivindicar una scultura de la extrañeza" -es decir, un sentido para todo aquello que se ha visto malogrado o que ha sido objeto de desposesión- basándose en la cuestión de la teodicea. En cualquier caso, actualmente la filosofía tiene menos que ver con la glorificación idealista de una realidad necesitada de redención que con la indiferencia frente a un mundo reducido empiristamente a una figura sin contornos y totalmente sordo para lo normativo.

Los frentes se han invertido. El historicismo - hoy dominante- de los paradigmas y las imágenes del mundo, es un empirismo de segundo nivel que resta seriedad a aquella pretensión de validez de carácter universalista que se halla detrás de toda afirmación y negación del sujeto que toma posición; una pretensión de validez que, si bien se sostiene siempre "ahora y aquí, en un contexto local, traspasa a su vez todos los criterios meramente provinciales. Si un paradigma o una imagen del mundo tiene el mismo valor que el siguiente, si diferentes discursos codifican cada uno a su manera todo aquello que puede ser verdadero o falso, bueno o malo, entonces debe clausurarse aquella dimensión normativa que nos permite sin más identificar los rasgos de una vida fracasada, adulterada e indigna de un ser humano, y experimentarla como una privación. Por ello, frente al olvido historicista del mismo olvido, también la filosofía recurre a la fuerza de la anamnesis. Pero ahora es la razón argumentativa misma la que, en las capas más profundas de sus propias presuposiciones pragmáticas, pone al descubierto las condiciones para la apelación a un sentido incondicionado $\mathrm{y}$, con ello, mantiene abierta la dimensión de las pretensiones de validez que trascienden Ios espacios sociales y los tiempos históricos. De este modo abre una brecha en la normalidad de un acontecer intramundano al que le falta todo rasgo promisorio; una normalidad que de otra forma quedaría cerrada a cal y canto frente a cualquier experiencia de ausencia de solidaridad y de justicia. Por supuesto que esta filosofía, que incorpora la idea de la alianza en el concepto de razón comunicativa históricamente situada, tampoco puede ofrecer ninguna firme esperanza; se halla bajo el signo de una "trascendencia desde dentron y debe contentarse con la exhortación fundamentada a una resistencia escéptica, pero no derrotista, "contra los ídolos y los demonios de un mundo que desprecia al ser humano».

La relación entre filosofía y teología vuelve a variar en el otro tema que, en términos de historia y política eclesiástica, más preocupa a Metz. Aquí la filosofía no solamente se esfuerza, como en la cuestión de la teodicea, en apropiarse los potenciales semánticos que se han conservado en la tradición religiosa, sino que incluso puede venir en ayuda de una teología que quiere clarificar la autocomprensión del cristianismo y de la Iglesia con respecto al pluralismo cultural y de concepciones del mundo..$^{10}$ 


\section{La Iglesia policéntrica universal}

Desde el Concilio Vaticano II la Iglesia se halla ante la doble tarea de, internamente, abrirse a la multiplicidad de las culturas en las que ha arraigado hasta ahora el cristianismo católico y, hacia el exterior, buscar un diálogo con las religiones de origen no cristiano, que no eluda la confrontación, en lugar de persistir en una apología defensiva. En ambas direcciones se plantea el mismo problema: ¿cómo puede mantener la Iglesia cristiana su identidad en la multiplicidad cultural de sus voces?; y ¿cómo puede la doctrina cristiana sostener la autenticidad de su búsqueda de la verdad en la disputa discursiva con imágenes del mundo concurrentes? Las respuestas que Metz ofrece son sugerentes. La Iglesia, que reflexiona en torno a los límites de su historia eurocéntrica a fin de armonizar la doctrina cristiana con la situación hermenéutica inicial de las culturas no-occidentales, no puede partir de la "idea de un cristianismo ahistórico, situado por encima de las culturas y étnicamente inocenten, sino que más bien debe tener presente tanto su origen teologico como su implicación institucional en la historia del colonialismo europeo. $Y$ un cristianismo que en el diálogo con otras religiones adopta una posición reflexiva respecto a su propia pretensión de verdad no puede darse por satisfecho con un "pluralismo sin relaciones mutuas o meramente condescendiente "; más bien debe atenerse firmemente, sin tendencia acaparadora y renunciando a todo medio de poder, a la validez universal de su oferta de salvación."

Con ello la Iglesia policéntrica parece adoptar casi una función ejemplar para la superación política del multiculturalismo. En sus relaciones internas parece un modelo recomendable para un Estado democrático de derecho que quiera hacer justicia a las diferentes formas de vida de una sociedad multicultural; y en sus relaciones externas una iglesia de este tipo podría tomarse como modelo de una comunidad de pueblos que regula sus relaciones internacionales sobre la base del reconocimiento recíproco. Sin embargo, visto más de cerca, el asunto funciona más bien a la inversa. Es la idea de la iglesia policéntrica la que, por su parte, se alimenta de las convicciones de la Ilustración europea y de su filosofía política.

Metz mismo se refiere afirmativamente a la herencia de un derecho natural racional ilustrado en términos hermenéuticos más allá de sus límites eurocéntricos: Europa es «el hogar cultural y político de un universalismo que en esencia es estrictamente antieurocéntrico... Ciertamente que el universalismo de la Ilustración, con su búsqueda de la libertad y la justicia, al principio solo fue universal en sentido semántico y, en su concreto proceso de ejecución, se ha mantenido particularista hasta hoy en día. Sin embargo, pone las bases de una nueva cultura política y herme- 
néutica que aspira al reconocimiento de la libertad inherente al sujeto y de la dignidad de todos los seres humanos. Este universalismo de los derechos humanos, desarrollado en las tradiciones europeas, no puede renunciar a la alteridad cultural. Mediante él se asegura que el pluralismo cultural no se desintegre simplemente en vago relativismo y que la postulada cultura de la sensibilidad mantenga su capacidad de ser verdaderas. ${ }^{12}$

Ahora bien, el cristianismo no puede esperar para sus concepciones de la historia de salvación y del orden de la creación -impregnadas de contenidos éticos-, un reconocimiento universal en el mismo sentido en el que puede hacerlo una teoría procedimental del derecho y de la moral en relación con los derechos humanos y los principios del Estado de derecho que pretende fundamentar apoyándose en un concepto de justicia procedimental. ${ }^{13}$ Es por ello por lo que el mismo Metz entiende la universalidad de la oferta de salvación más bien como una «invitación» dirịgida a todos -que debe acreditarse prácticamente- y no como aquella pretensión universal de aceptabilidad racional con la que, por. ejemplo, se presentaba el derecho natural racional. Incluso la Iglesia policéntrica universal continúa siendo, en las sociedades modernas, una comunidad de interpretación entre otras muchas, cada una de las cuales articula su propia concepción de la salvación, su propia idea de lo que es una vida no fallida y que polemizan entre ellas en torno a la interpretación más convincente de la justicia, la solidaridad y la liberación de la miseria y la humillación. La Iglesia debe internalizar este punto de vista externo, apropiárselo como una mirada que dirige a sí misma. Y, para ello, se sirve de las ideas desarrolladas en la Ilustración europea; precisamente aquellas ideas que hoy deben prevalecer tanto en las sociedades multiculturales organizadas democráticamente como en las relaciones de reconocimiento -estructuradas en términos de derechos humanos- entre los pueblos y culturas de este mundo.

Los derechos fundamentales y los principios del Estado de derecho constituyen, en las sociedades multiculturales, los puntos de cristalización para una cultura política que incluya a todos los ciudadanos; esta cultura política es, a su vez, el fundamento para una coexistencia igualitaria de diferentes grupos y subculturas, cada uno de ellos con un origen y una identidad propios. El desacoplamiento de estos dos niveles de integración es el presupuesto para que la cultura mayoritaria no ejerza por más tiempo el poder de definir la cultura política común, sino que más bien se someta a ella y se abra a un intercambio, libre de coacciones, con las culturas minoritarias. Una situación comparable es la que existe en el seno de la Iglesia policéntrica universal: en ella debe formarse una autocomprensión cristiana común que deje de coincidir con las tradiciones occidentales que han sido históricamente determinantes y que represente meramente el trasfon- 
do sobre el cual tales tradiciones se percaten de sus limitaciones y especificidades eurocéntricas.

Pero, en lo que se refiere a su relación con otras religiones, al cristianismo católico se le exige en general otro tipo de autorreflexión hermenéutica. Aquí no sirve la analogía con un mundo occidental decidido a mantener, en la escena internacional, un trato descentrado y abierto al aprendizaje con las culturas no-occidentales. Pues, para ello, suponemos como base común unos derechos humanos que presuntivamente disfrutan de un reconocimiento general y racionalmente motivado. Sin embargo, en la disputa dialógica entre imágenes religiosas y metafísicas del mundo se carece de una concepción común del bien que sirva de equivalente a aquella base jurídico-moral común. De modo que esta disputa debe dirimirse con la plena consciencia reflexiva de que todos los implicados se mueven en el mismo universo de discurso y se respetan mutuamente como participantes cooperativos en la búsqueda de la verdad ético-existencial. Para ello, se precisa una cultura del reconocimiento cuyos primeros principios se extraen del mundo secularizado de un universalismo tan propio de la moral como del derecho natural racional. Así pues, en esta cuestión, es el espíritu filosófico de la Ilustración política el que ofrece a la teología los conceptos que le permiten explicarse el sentido de su marcha hacia una Iglesia policéntrica. Y no digo esto por el simple afán de tener razón, sino porque tal filosofia política lleva grabada la idea de la Alianza al menos tan profundamente como la idea de la Polis. Por ello invoca también una herencia bíblica, que es a la que apela Metz cuando recuerda a la Iglesia contemporánea que «en nombre de su misión» tiene que «buscar libertad y justicia para todos" y guiarse por «una cultura del reconocimiento de los otros en su diferente forma de serm.14

\section{NOTAS}

1. J,B, Metz, Unterbrechungen, Gütersloh, 1981, 13.

2. KJ. Kuschel (ed.), Dorothee Sölle und Johann Baptist Metz im Gespradch, Stuttgart, 1990,23 y ss.

3. J.B. Metz, Jenseits bürgerlicher Religion, Múnich, 1980.

4. J.B. Metz, «Anamnetische Vemunft", en A. Honneth et al. (eds.), Zwischenbetrachtungen, Francfort, 1989, 733 ss.

5. J.B. Metz, "Die Rede von Gott angesichts der Leidensgeschichte der Welt", Stimmen der Zeit, 5 (1992), 24.

6. Ibid.

7. J.B. Metz, "Im Angesicht der Juden. Christliche Theologie nach Auschwitz», en Concilium, 20 (1984), 382-389.

8. Metz (1992); M. Theunissen habla en este contexto de un ufuturo prolépticom, Vid. J. Habermas, "Kommunikative Freiheit und negative Theologie", en E. Angehrn et aI. (eds.), Dialektischer Negativismus, Francfort, 1992, 15-34.

9. M. Theunissen, Negative Theologie der Zeit, Francfort, 1991, 368. 
10. J.B. Metz, «Theologie im Angesicht und vor dem Ende der Modeme*, en Concitium, $20(1984), 14-18$.

11. J.B. Metz, «Im Aufbruch zu einer kulturell polyzentrischen Weltkirche», en Kaufmann, Metz, Zukunftsfähigkeit, Friburgo, 1987, 93-115.

12. J.B. Metz, Perspektiven eines multikuliurellen Christentum, manuscrito, diciembre 1992.

13. J. Rawls, A Theory of Justice, Cambridge, MA, 1971; J, Habermas, Faktizität und Geltung, Francfort, 1992.

14. Metz (1987), 118. 